\title{
Hyperactivation of mammalian spermatozoa: function and regulation
}

\author{
Han-Chen Ho and Susan S. Suarez* \\ Department of Biomedical Sciences, College of Veterinary Medicine, Cornell University, \\ Ithaca, NY 14853, USA
}

\begin{abstract}
Hyperactivation is a movement pattern observed in spermatozoa at the site and time of fertilization in mammals. It may be critical to the success of fertilization, because it enhances the ability of spermatozoa to detach from the wall of the oviduct, to move around in the labyrinthine lumen of the oviduct, to penetrate mucous substances and, finally, to penetrate the zona pellucida of the oocyte. The movement of hyperactivated spermatozoa appears different under different physical conditions and in different species, but basically it involves an increase in flagellar bend amplitude and beat asymmetry. Presumably, there is a signal or signals in the oviduct to initiate hyperactivation at the appropriate time; however, none has yet been identified. There is evidence that the source of the signal is follicular fluid, yet spermatozoa are known to hyperactivate before ovulation would release the fluid into the oviduct. Although the signal transduction cascade regulating hyperactivation remains to be described completely, it is clear that calcium ions interact with the axoneme of the flagellum to switch on hyperactivation. The process may also involve increases in intracellular cAMP, which at least is required to support motility in general. Although hyperactivation usually occurs during capacitation, the two events are regulated by different pathways.
\end{abstract}

Hyperactivated movement of spermatozoa was first reported by Yanagimachi (1969), who observed that, as spermatozoa gained the ability to fertilize oocytes in vitro, their flagella began beating more vigorously than before. He proposed that the vigorous beating plays a vital role in the penetration of the zona pellucida.

Yanagimachi's proposal that hyperactivated motility enables spermatozoa to penetrate the zona pellucida was later confirmed by experiments. Stauss et al. (1995) used various methods that prevented hyperactivation but did not inhibit the acrosome reaction, and demonstrated that hyperactivated hamster spermatozoa were more successful at penetrating the zonae pellucidae of oocytes in vitro than spermatozoa that were not hyperactivated.

Additional functions have been ascribed to hyperactivation. These were based on consideration of the obstacles encountered by spermatozoa in the oviduct. Mucus is present in the isthmus of the oviduct of rabbits (Jansen, 1978), humans (Jansen, 1980), pigs (Suarez et al., 1992) and cattle (Suarez et al., 1997). In many species, spermatozoa also encounter another type of mucus, consisting primarily of hyaluronic acid, while passing through the cumulus oophorus. Mucus increases the

*Correspondence

Email:sss7@cornell.edu viscosity and elasticity of the aqueous milieu in which spermatozoa swim. Both hamster (Suarez et al., 1991) and mouse (Suarez and Dai, 1992) spermatozoa penetrated viscoelastic substances more effectively when they were hyperactivated; therefore, hyperactivated spermatozoa are likely to be more effective at penetrating oviductal mucus and the cumulus matrix in vivo.

The behaviour of hamster and mouse spermatozoa within transilluminated oviducts indicated that hyperactivation enables spermatozoa to move about effectively in the lumen until they encounter the oocyte. Hyperactivated spermatozoa placed on a microscope slide in simple aqueous medium often spend a lot of time swimming in circles, whereas within the oviduct, the walls of which are not hard and flat like those of a slide, hyperactivated spermatozoa appear to cover space effectively in a search pattern. Mouse spermatozoa used the deep flagellar bends characteristic of hyperactivation to turn around within pockets of mucosa and escape out into the central lumen (Suarez and Osman, 1987). Hyperactivated hamster spermatozoa glided rapidly over the mucosal surface of the ampulla (Katz and Yanagimachi, 1980).

In several species of mammal, a reservoir of spermatozoa forms within the isthmus of the oviduct. The reservoir is thought to preserve spermatozoa and ensure that they are in the proper state for fertilization when oocytes enter the oviduct, and is formed when spermatozoa are trapped by 

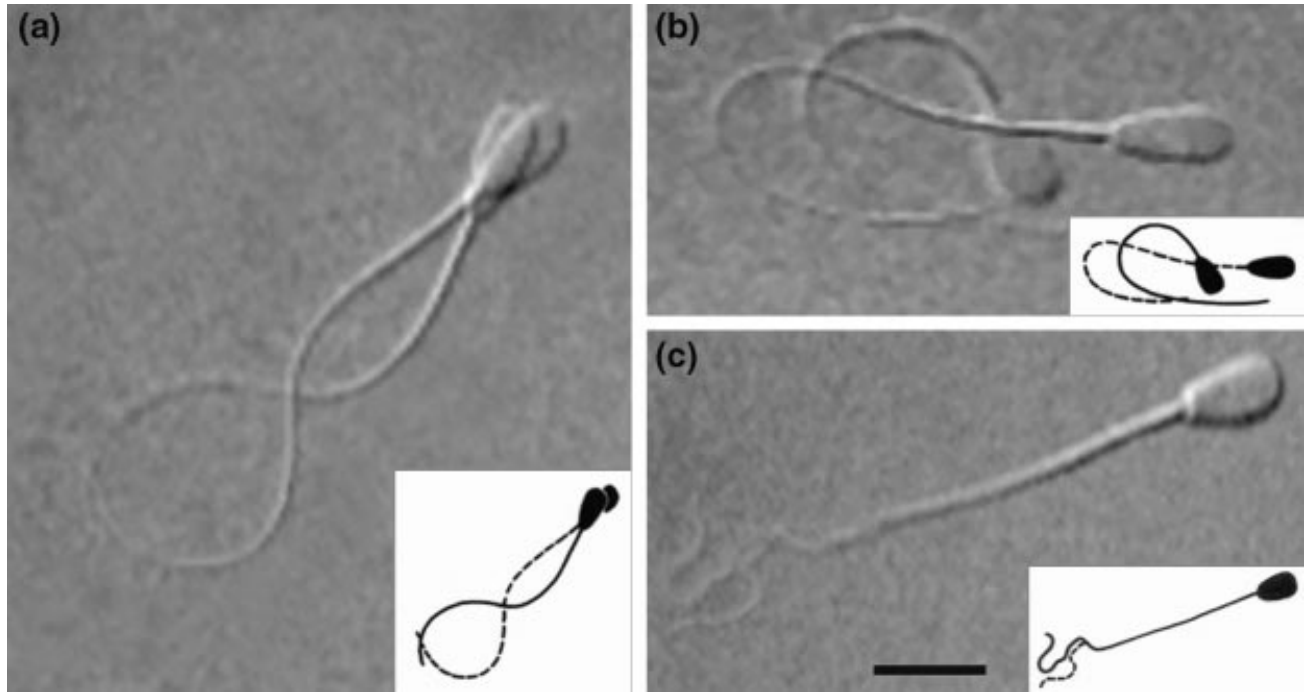

Fig. 1. Video images of swimming patterns of hyperactivated bull spermatozoa on glass slides in shallow chambers approximately $10 \mu \mathrm{m}$ deep. Spermatozoa were illuminated by flashes from a xenon strobe at $60 \mathrm{~Hz}$. Video frames were captured at $30 \mathrm{~Hz}$ by a Dage CCD 72 camera and digitized using a Scion CG-7 imaging board. Each image represents two consecutive video fields spaced 1/60 s apart. Traces of the images are shown in insets. (a) The symmetrical flagellar beat pattern of activated spermatozoa. (b) The asymmetrical flagellar beat pattern of hyperactivated spermatozoa. (c) The progressive swimming of hyperactivated spermatozoa in a thick, viscoelastic solution of long-chain polyacrylamide. Scale bar represents $10 \mu \mathrm{m}$.

sticking to the mucosal epithelium. In hamsters, horses and cattle, this interaction is mediated by carbohydrate recognition, that is, a lectin-like molecule on the surface of spermatozoa binds to a specific oligosaccharide moiety on the epithelium (DeMott et al., 1995; Suarez et al., 1998). In cattle, the lectin-like molecule has been identified as PDC109 (also known as BSP-A1/A2), a protein secreted by the seminal vesicles that coats the heads of ejaculated spermatozoa (Ignotz et al., 2001). Loss or modification of the molecule apparently releases spermatozoa from the epithelium (Ignotz et al., 2001). Release may be assisted by hyperactivation. During examination of the movements of mouse spermatozoa within the oviduct, DeMott and Suarez (1992) noticed that only spermatozoa showing hyperactivated movement pulled away from the epithelium. Hyperactivation may pull spermatozoa off the epithelium as their hold on the oligosaccharide moiety weakens.

\section{Definition of hyperactivation}

It is difficult to define hyperactivation precisely and globally by the physical characteristics of the swimming pattern. The pattern of sperm movement varies among species and according to the physical environment in which spermatozoa swim. It is best to define hyperactivated motility in comparison with activated motility for each particular species and to do so for spermatozoa swimming in a physiological liquid medium on a slide. Activated motility is defined by Yanagimachi (1994) as follows. Spermatozoa within the epididymis are inactive or only weakly motile. When they are released into seminal plasma in vivo or into physiological medium in vitro, they rapidly begin to swim vigorously in a nearly straight trajectory (Fig. 1a). Hyperactivated motility is defined as the swimming pattern shown by most spermatozoa retrieved from the oviductal ampulla at fertilization. The flagella of hyperactivated spermatozoa are thrown into deeper bends and their beating is usually less symmetrical than that of flagella of activated spermatozoa (Figs 1 and 2). As a result, hyperactivated spermatozoa tend to swim vigorously in circles on a microscope slide. In some species, spermatozoa that are fully hyperactivated complete a circle in two flagellar beats, giving the appearance of swimming in figures-of-eight.

Some authors have described hyperactivation as biphasic, because they observed spermatozoa alternating between the activated and hyperactivated swimming patterns (Johnson et al., 1981; Tessler and Olds-Clarke, 1985). It could be argued that this is the result of hyperactivation being switched on and off. As discussed below, very little is known about the mechanisms that regulate hyperactivation; therefore, it is impossible to know whether hyperactivation is truly biphasic.

One factor affecting the flagellar beating pattern, which results in variation in patterns of activation and hyperactivation among species, is the rate of rotation of spermatozoa about the longitudinal axis (rolling, Fig. 2). Activated rabbit, bull and boar spermatozoa roll rapidly as they swim. Freshly activated hamster spermatozoa roll rarely and appear to glide along on slides in a gently curved path 

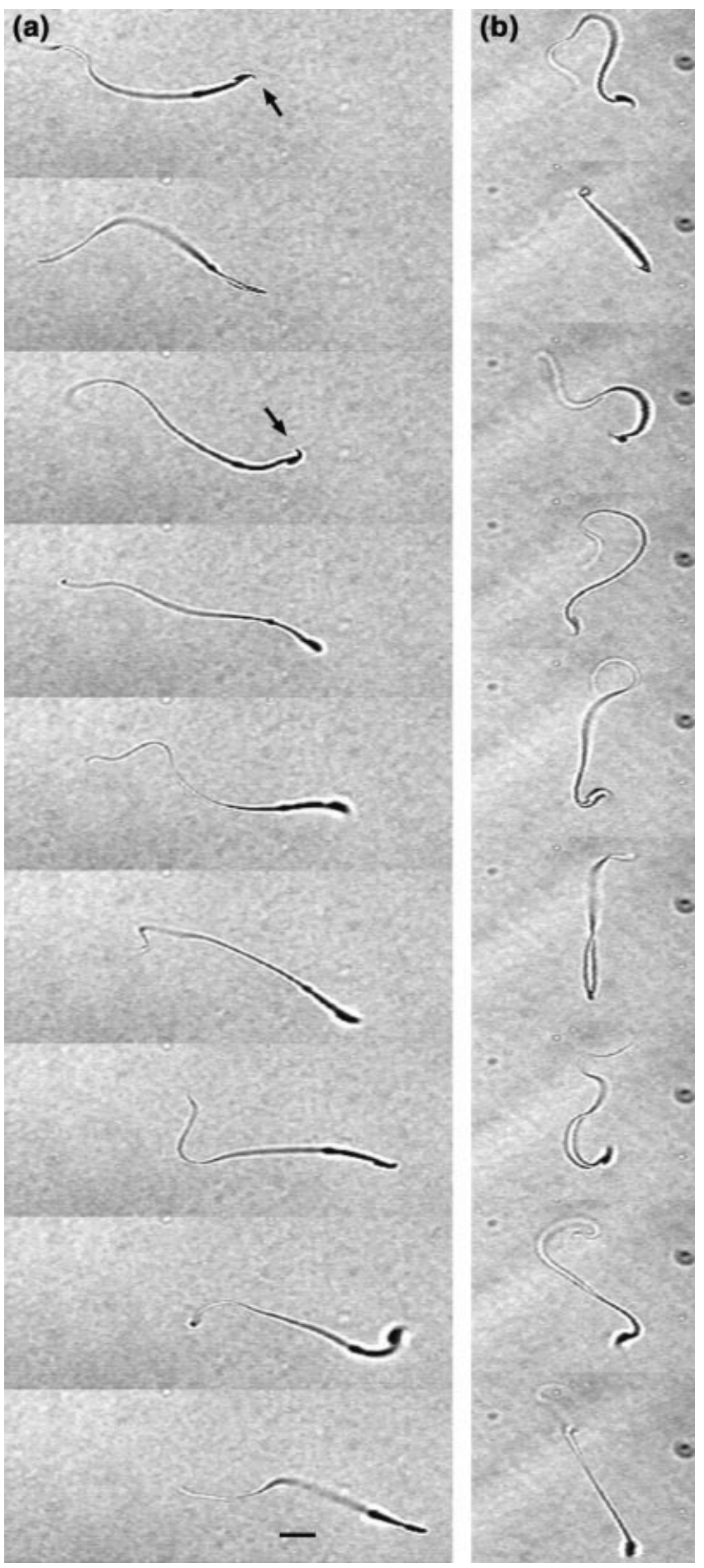

Fig. 2. Phase-contrast video images of (a) activated and (b) hyperactivated mouse spermatozoa. Consecutive images were collected at $30 \mathrm{~Hz}$ and each series begins at the top of the plate. Rotation of the spermatozoa about its long axis (rolling) can be seen by noting the position of the hook on the head (arrows). Scale bar represents $10 \mu \mathrm{m}$.
(Suarez, 1988). After 2-3 h of incubation under capacitating conditions, rolling increases and they swim in a helical pattern. Rolling is diminished once again at hyperactivation, so the spermatozoa trace out small circles (Suarez, 1988). Rolling that occurs once per beat cycle produces a helical path, whereas rolling that occurs intermittently causes a change in the direction of swimming. Thus, rolling has the potential to provide a chemotactic response.

A second factor that affects swimming patterns is the thickness of the outer dense fibres in the flagellum (Fig. 3) (Phillips, 1972). Species showing a small radius of curvature in flagellar bends (mice, humans, rabbits, opossums) tend to have smaller outer dense fibres than do species showing a large radius of curvature in the flagellar bend (rats, Chinese hamsters).

Two additional factors that affect flagellar movement patterns are apparently unique to marsupial spermatozoa. Spermatozoa of American opossums (Monodelphis domestica, Didelphis virginiania) are bound together by the heads, forming a biflagellate organism; the pairs separate before fertilization. Spermatozoa of Monodelphis domestica, obtained from the distal caudal epididymis, were paired and swam progressively, with flagella beating synchronously, until a few hours of incubation in fertilization medium (Moore and Taggart, 1993). Subsequently, some pairs began to beat asynchronously until the spermatozoa pulled apart. At this stage, some of the single spermatozoa showed a 'whiplash' flagellar movement resembling hyperactivation. Only unpaired spermatozoa bound to the zona pellucida. In some Australian marsupials, the joint between the head and flagellum is modified in the oviduct before fertilization, such that the longitudinal axis of the head shifts from being in alignment with the flagellum, to orienting perpendicularly to the flagellum (Bedford and Breed, 1994).

Because of species differences in movement patterns, objective evaluation of hyperactivation using computerassisted sperm analysis (CASA) must be determined for each species. A common procedure is to incubate spermatozoa under capacitating conditions and compare swimming patterns with spermatozoa that have not been exposed to capacitating conditions. A particular subset of movement patterns observed to increase under capacitating conditions is categorized as hyperactivated. The incidence of hyperactivation is assayed by setting threshold values for movement measurement variables that distinguish this subgroup from others (mouse: Neill and Olds-Clarke, 1987; human: Mortimer and Swan, 1995; ram: Mortimer and Maxwell, 1999; rat: Cancel et al., 2000). It should be noted that most CASA systems operate by measuring the movements of the head, which measures flagellar movement only indirectly.

\section{A physiological signal for hyperactivation?}

Hyperactivation must be switched on at the right place and time to achieve fertilization. Thus, it is likely that there are 


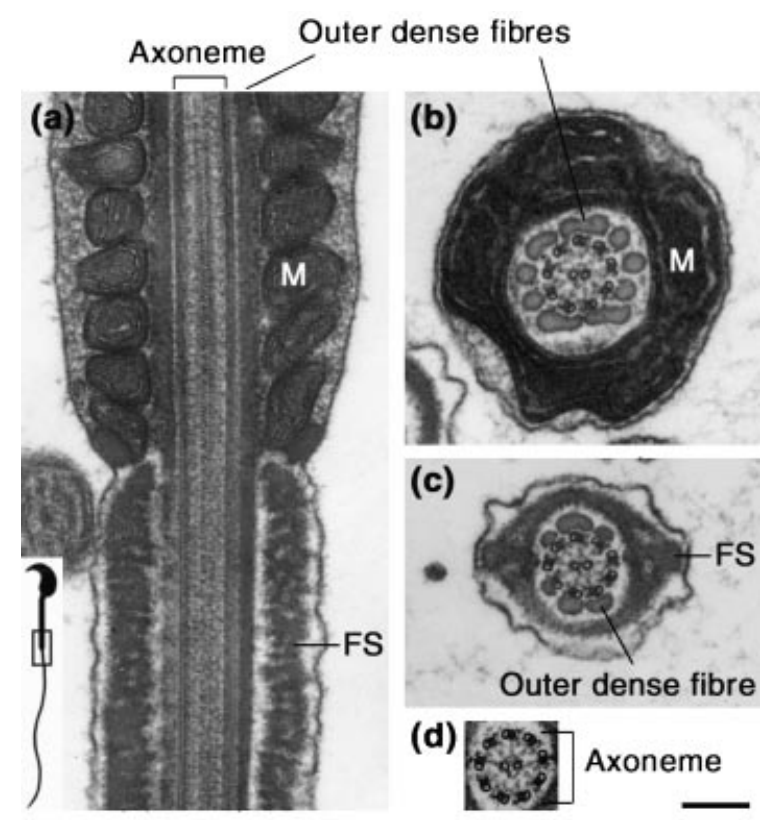

Fig. 3. (a) Longitudinal section of the junction of the midpiece and principal piece of a mouse spermatozoon (boxed area shown in inset). The axoneme, consisting of microtubules, dynein ATPase and associated proteins, is in the core of the flagellum. It is surrounded by outer dense fibres and mitochondria $(M)$ in the midpiece, and by fibrous sheath (FS) in the principal piece. $(b, c)$ Cross-sections of the midpiece and principal piece, respectively. (d) Cross-section of the axoneme alone, showing the typical ' $9+2$ ' pattern, with a central pair of microtubules surrounded by nine sets of doublets. Scale bar represents $200 \mathrm{~nm}$.

one or more specific signals within the female reproductive tract for regulating hyperactivation. There is evidence that various components of the female reproductive tract may serve as physiological stimuli of hyperactivation. Hormones, ions and secretions in the oviductal luminal fluid vary during the oestrous cycle (Nichol et al., 1992). When the oocyte enters the oviduct, it usually brings with it cumulus oophorus and follicular fluid, which influence sperm motility.

Human follicular fluid has a dose-dependent effect on flagellar beat frequency and hyperactivation (Yao et al., 2000). It was suggested that progesterone is the active factor, because it enhances hyperactivation (Sueldo et al., 1993). However, progesterone did not stimulate hyperactivation in at least one study (Kay et al., 1994) and it seems unlikely that progesterone alone induces hyperactivation, because progesterone receptors are confined to the human sperm head (Blackmore and Lattanzio, 1991).

Cumulus cells that enter the ampulla with the oocyte may also provide signals for hyperactivation. Culture medium exposed to cumulus oophorus cells increases curvilinear velocity and amplitude of lateral head displacement of human spermatozoa (Fetterolf et al., 1994).

Despite evidence from experiments in vitro for a role of follicular fluid and cumulus in initiating hyperactivation, evidence in vivo argues that these factors alone cannot be responsible for initiating hyperactivation. Hyperactivated spermatozoa have been detected in the oviduct before ovulation in rabbits (Cooper et al., 1979) and mice (Suarez and Osman, 1987). Although follicular fluid was found to reach the oviductal ampulla at ovulation in pigs, only $<1 \%$ of the fluid was retained in the ampullary lumen (Hansen et al., 1991); an even smaller amount would reach the spermatozoa stored in the reservoir in the caudal isthmus. Alternatively, the follicle may communicate with the spermatozoa in the isthmus while still in the ovary. There is anatomical evidence for a vascular counter-current transfer of follicular hormones from veins leaving the ovary to arteries supplying the wall of the isthmus (Hunter et al., 1983).

Although follicular fluid and cumulus components have been observed to induce hyperactivation, no specific signals have been identified unequivocally.

\section{Mechanisms regulating hyperactivation}

A number of physiological factors, such as $\mathrm{Ca}^{2+}$, cAMP, bicarbonate and metabolic substrates, are essential for the initiation and maintenance of hyperactivated motility in vitro.

$\mathrm{Ca}^{2+}$ plays a major role in regulating hyperactivated motility. Extracellular $\mathrm{Ca}^{2+}$ is required to maintain hyperactivation in hamster spermatozoa in vitro (Yanagimachi, 1994), and treatment of mouse spermatozoa with $\mathrm{Ca}^{2+}$ ionophore A23187 rapidly induces hyperactivated motility (Suarez et al., 1987). Cytoplasmic $\mathrm{Ca}^{2+}$ concentrations within the flagella of hyperactivated hamster spermatozoa are higher than those in activated spermatozoa (Suarez et al., 1993). A demembranated sperm model (treating spermatozoa with Triton-X100 to disrupt plasma membrane and mitochondrial membranes, essentially leaving only the axoneme and cytoskeletal support (Fig. 3)) has been used to study hyperactivated motility. When rat and bull spermatozoa were treated with Triton-X100, they began swimming if ATP and CAMP were added and became hyperactivated if $\mathrm{Ca}^{2+}$ was added (Lindemann and Goltz, 1988; Lindemann et al., 1991). These studies indicate that the crucial site for the action of $\mathrm{Ca}^{2+}$ is the axoneme (Fig. 3). However, the mechanism by which $\mathrm{Ca}^{2+}$ reaches the axoneme in the core of the flagellum to switch on hyperactivation in intact spermatozoa is still unknown.

Procaine-treated guinea-pig spermatozoa undergo hyperactivation in $\mathrm{Ca}^{2+}$-deficient medium (Mujica et al., 1994), indicating that there may be an intracellular $\mathrm{Ca}^{2+}$ store in the flagellum to provide increased $\mathrm{Ca}^{2+}$ to the axoneme. Inositol 1,4,5-trisphosphate $\left(\mathrm{IP}_{3}\right)$ releases $\mathrm{Ca}^{2+}$ from some stores, and $\mathrm{IP}_{3}$ receptors have been localized by antibodies to the base of the flagellum (Walensky and Snyder, 1995). Heterotrimeric $G$ proteins of the $G_{q / 11}$ family selectively activate the $\beta$ isoforms of the phosphatidylinositidespecific phospholipase $C$ to produce $\mathrm{IP}_{3}$. Both $\mathrm{G} \alpha_{\mathrm{q} / 11}$ and 
phospholipase C- $\beta$ have been localized along the midpiece of rat sperm flagella (Walensky and Snyder, 1995).

In addition to the $\mathrm{IP}_{3}$ receptor-gated $\mathrm{Ca}^{2+}$ store, extracellular $\mathrm{Ca}^{2+}$ may be required to maintain hyperactivation for long periods by replenishing the intracellular store and maintaining high cytoplasmic $\mathrm{Ca}^{2+}$. When extracellular $\mathrm{Ca}^{2+}$ was unavailable, hyperactivated hamster spermatozoa reverted to activated motility (Yanagimachi, 1994). Cyclic nucleotide-gated channels have been localized to bull sperm flagella (Wiesner et al., 1998); therefore, activation of cyclic nucleotide-gated channels by cAMP/cGMP may be one of the mechanisms providing $\mathrm{Ca}^{2+}$ entry.

Increased intracellular cAMP has been associated with the expression of hyperactivated motility (White and Aitken, 1989). Aoki et al. (1999) proposed that cAMP might be involved in the regulation of flagellar waveform by maintaining $\mathrm{Ca}^{2+}$ at an appropriate concentration. $\mathrm{Ca}^{2+}$ and cAMP may also modulate protein phosphorylation (Tash, 1989). Increased protein tyrosine phosphorylation in flagella is associated with hyperactivated motility in hamster ( $\mathrm{Si}$ and Okuno, 1999) and monkey spermatozoa (Mahony and Gwathmey, 1999). Tyrosine phosphorylation has also been associated with heat-induced hyperactivation in human spermatozoa (Chan et al., 1998). Tyrosine phosphorylation, dephosphorylation and rephosphorylation of an $80 \mathrm{kDa}$ protein in hamster sperm flagella are tightly associated with the acquisition, loss and reacquisition of temperaturedependent hyperactivation (Si, 1999). As dephosphorylation has been observed, phosphatases are also presumed to be involved in the regulation of hyperactivation.

Bicarbonate supports hyperactivation in mouse spermatozoa (Neill and Olds-Clarke, 1987), possibly by modulating the activity of adenylyl cyclase in the flagellum (Okamura et al., 1985). A soluble form of mammalian adenylyl cyclase has been purified and cloned recently, and can be stimulated directly by bicarbonate (Chen et al., 2000). It will be informative to determine whether bicarbonate regulates sperm motility through direct activation of the soluble adenylyl cyclase.

Although CAMP and $\mathrm{Ca}^{2+}$ regulate hyperactivated motility through different pathways, they also modulate the actions of each other. $\mathrm{Ca}^{2+}$ causes marked increases in cAMP and activates the $\mathrm{Mg}^{2+}$-dependent adenylyl cyclase of guinea-pig spermatozoa (Hyne and Garbers, 1979). In spermatozoa treated with Triton-X100 to remove the plasma and mitochondrial membranes, the response to $\mathrm{Ca}^{2+}$ appears to require cAMP priming (Lindemann et al., 1991). However, Mujica et al. (1994) showed that cAMP was present at high concentrations in guinea-pig spermatozoa independent of hyperactivtion. It appears that CAMP is required but is not sufficient for hyperactivation.

It should be stressed that $\mathrm{Ca}^{2+}$ is responsible for increasing flagellar asymmetry, which is characteristic of hyperactivated motility, whereas CAMP is a major factor in the initiation and maintenance of flagellar beats. In a study using sea urchin spermatozoa as a model, selective regulation of the activity of a group of dynein arms by $\mathrm{Ca}^{2+}$ was demonstrated to be the basis for the changes in flagellar bending patterns brought about by high $\mathrm{Ca}^{2+}$ concentrations (Bannai et al., 2000). As calmodulin is known to be responsible for increasing the asymmetry of the flagellar waveform in the presence of $\mathrm{Ca}^{2+}$ above $10^{-6} \mathrm{~mol} \mathrm{I}^{-1}$ (Brokaw, 1991), it is possible that a $\mathrm{Ca}^{2+}$-calmodulin complex regulates the activity of dynein through protein phosphorylation.

In summary, it appears that $\mathrm{Ca}^{2+}$ is the most important factor regulating hyperactivation, and that CAMP is required but is not sufficient for expression of hyperactivation. A hypothetical model for regulation of hyperactivation is proposed (Fig. 4).

\section{Hyperactivation and chemotaxis/chemokinesis}

Chemotaxis has been well documented in invertebrates, in which very low concentrations of peptides, such as speract secreted by sea urchin eggs, attract spermatozoa in a speciesspecific manner. The peptides facilitate fertilization by binding to sperm receptors and thereby stimulating motility and respiration. Cook et al. (1994) demonstrated that intracellular $\mathrm{Ca}^{2+}$ mediates chemotaxis in sea urchin spermatozoa, whereby increases in intracellular $\mathrm{Ca}^{2+}$ enhance flagellar bend asymmetry and swimming path curvature. In a similar way to chemotactic responses of sea urchin spermatozoa, hyperactivated mammalian spermatozoa display increased flagellar bend asymmetry and change direction frequently. These movements could allow spermatozoa to reach the oocyte. Analogous ligand-receptor interactions in vertebrates have not been characterized, although human spermatozoa are attracted by follicular fluid in vitro (Ralt et al., 1994).

Odorant-like molecules could function as chemoattractants to spermatozoa to guide them to the oocyte. Antibodies to a conserved region of odorant receptors specifically labelled mature dog spermatozoa (Vanderhaeghen et al., 1993) and the base of the flagellum and the proximal midpiece of mature rat spermatozoa (Walensky et al., 1995). These antibodies also detected odorant receptors in western blots of protein extracts of hamster and human spermatozoa (Walensky et al., 1995). In permeabilized preparations of olfactory cilia, odorants were found to stimulate CAMP and $\mathrm{IP}_{3}$ production (Pace et al., 1985). In the base of the sperm flagellum, putative chemotactic ligand-receptor interactions could produce an $\mathrm{IP}_{3}$-induced release of $\mathrm{Ca}^{2+}$, which may, in turn, contribute to high intracellular $\mathrm{Ca}^{2+}$ concentrations where the flagellar bend initiates and to a subsequent change in motility.

Speract activates a transmembrane guanylyl cyclasereceptor complex and apparently utilizes cGMP to activate sea urchin sperm $\mathrm{K}^{+}$channels; speract also causes a transient increase in CAMP and $\mathrm{Ca}^{2+}$ (Cook and Babcock, 1993). Cyclic nucleotide-gated channels have been localized along the midpiece and principal piece of bull spermatozoa, and activation of these channels increases intracellular $\mathrm{Ca}^{2+}$ (Wiesner et al., 1998). The localization of cyclic nucleotide-gated channels along the flagellum 


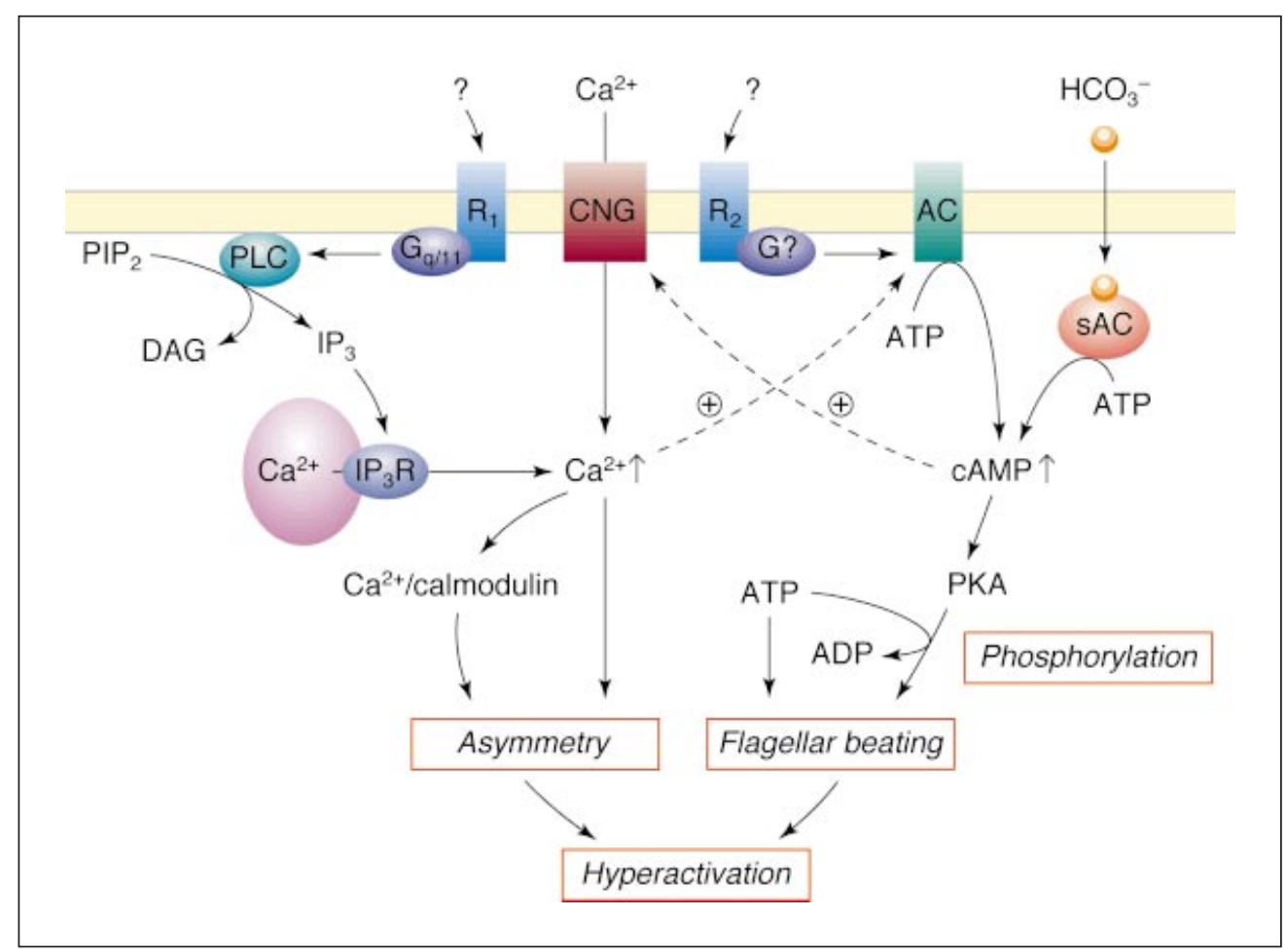

Fig. 4. A hypothetical model for mechanisms regulating hyperactivation. Upon signal stimulation, pathways leading to increases in $\mathrm{Ca}^{2+}$ and $\mathrm{cAMP}$ are turned on. Unknown physiological signals activate phospholipase $C(P L C)$ through a heterotrimeric $G$ protein $\left(G_{q / 11}\right)$-coupled receptor $\left(R_{1}\right)$ and produce $I_{3}$. Binding of $\mathbb{I P}_{3}$ to $\mathbb{I P}_{3}$ receptors $\left(\mathrm{IP}_{3} \mathrm{R}\right)$ causes an increase in cytoplasmic $\mathrm{Ca}^{2+}$. Activation of the membrane-associated adenylyl cyclase (AC) through high cytoplasmic $\mathrm{Ca}^{2+}$ and possibly $\mathrm{G}$ proteins $(G$ ?) and membrane potential increases intracellular cAMP. Bicarbonate may also cause an increase in cAMP by activating the soluble form of adenylyl cyclase (sAC) directly. The increased cAMP can bind to cyclic nucleotide-gated channels (CNG) to induce $\mathrm{Ca}^{2+}$ influx. Increased cAMP activates protein kinase A (PKA) to phosphorylate axonemal or fibrous sheath proteins and results in flagellar beating. High cytoplasmic $\mathrm{Ca}^{2+}$ and $\mathrm{Ca}^{2+}-$ calmodulin complex are responsible for asymmetrical bending of flagella that is characteristic of hyperactivation.

implies that flagellar bending waves could be regulated in a chemotactic-like manner.

\section{Hyperactivation and capacitation}

The physiological changes that allow spermatozoa to undergo the acrosome reaction are collectively called 'capacitation' (Yanagimachi, 1994). Although hyperactivation usually occurs at some point during capacitation in vitro, the pathways leading to hyperactivation and capacitation are not coupled completely. Boatman and Robbins (1991) found that bicarbonate is essential for both capacitation and hyperactivation of hamster spermatozoa in vitro, but hyperactivation required higher concentrations of bicarbonate than did capacitation. Hyperactivation can proceed independently of capacitation in mouse and hamster spermatozoa. Spermatozoa from $t^{w 32} /+$ mouse show hyperactivated motility prematurely in vitro, whereas capacitation occurs on schedule (Neill and Olds-Clarke, 1987; Olds-Clarke, 1989). In hamster spermatozoa, medium with certain energy substrates (BSA, adrenaline, hypotaurine and penicillamine) allows full development of hyperactivation, which precedes capacitation by $\geqslant 1 \mathrm{~h}$ (DeMott et al., 1995). Procaine can initiate hyperactivation rapidly in uncapacitated guinea-pig spermatozoa (Mujica et al. 1994). Thus, hyperactivation and capacitation should be considered as independent events.

\section{Conclusions}

Hyperactivated motility appears to be critical to the process of fertilization in vivo, allowing spermatozoa to reach the oocyte through the narrow, mucus-filled, labyrinthine lumen of the oviduct and assisting spermatozoa in penetrating the cumulus oophorus and the zona pellucida. The signal initiating hyperactivation in the oviduct has not been identified; however, $\mathrm{Ca}^{2+}$ is a critical element in the signalling pathway to convert symmetrical bending to the asymmetrical bending that is characteristic of hyperactivation. This vigorous movement also requires ATP and 
cAMP. Determining how hyperactivation is initiated in the oviduct would provide valuable information in the diagnosis and treatment of infertility or in the development of new methods of contraception that prevent spermatozoa from reaching the oocyte.

\section{References}

Key references are identified by asterisks.

Aoki F, Sakai S and Kohmoto K (1999) Regulation of flagellar bending by cAMP and $\mathrm{Ca}^{2+}$ in hamster sperm Molecular Reproduction and Development 53 77-83

Bannai H, Yoshimura M, Takahashi K and Shingyoji C (2000) Calcium regulation of microtubule sliding in reactivated sea urchin sperm flagella Journal of Cell Science 113 831-839

Bedford JM and Breed WG (1994) Regulated storage and subsequent transformation of spermatozoa in the Fallopian tubes of an Australian marsupial, Sminthopsis crassicaudata. Biology of Reproduction $\mathbf{5 0}$ 845-854

Blackmore PF and Lattanzio FA (1991) Cell surface localization of a novel non-genomic progesterone receptor on the head of human sperm Biochemical and Biophysical Research Communications 181 331-336

Boatman DE and Robbins RS (1991) Bicarbonate: carbon-dioxide regulation of sperm capacitation, hyperactivated motility, and acrosome reactions Biology of Reproduction 44 806-813

Brokaw CJ (1991) Calcium sensors in sea urchin sperm flagella Cell Motility and the Cytoskeleton 18 123-130

Cancel AM, Lobdell D, Mendola P and Perreault SD (2000) Objective evaluation of hyperactivated motility in rat spermatozoa using computer-assisted sperm analysis Human Reproduction 15 1322-1328

Chan PJ, Corselli JU, Patton WC, Jacobson JD and King A (1998) Enhanced fertility after heat-induced hyperactivation Fertility and Sterility $\mathbf{6 9}$ 118-121

*Chen Y, Cann MJ, Litvin TN, lourgenko V, Sinclair ML, Levin LR and Buck J (2000) Soluble adenylyl cyclase as an evolutionarily conserved bicarbonate sensor Science 289 625-628

Cook SP and Babcock DF (1993) Activation of $\mathrm{Ca}^{2+}$ permeability by cAMP is co-ordinated through the $\mathrm{pH}$ increase induced by speract Journal of Biological Chemistry 26822 408-22 413

Cook SP, Brokaw CJ, Muller CH and Babcock DF (1994) Sperm chemotaxis: egg peptides control cytosolic calcium to regulate flagellar responses Developmental Biology 165 10-19

Cooper GW, Overstreet JW and Katz DF (1979) The motility of rabbit spermatozoa recovered from the female reproductive tract Gamete Research 2 35-42

DeMott RP and Suarez SS (1992) Hyperactivated sperm progress in the mouse oviduct Biology of Reproduction 46 779-785

DeMott RP, Lefebvre R and Suarez SS (1995) Carbohydrates mediate the adherence of hamster sperm to oviductal epithelium Biology of Reproduction 52 1395-1403

Fetterolf PM, Jurisicova A, Tyson JE and Casper RF (1994) Conditioned medium from human cumulus oophorus cells stimulates human sperm velocity Biology of Reproduction 51 184-192

Hansen C, Srikandakumar A and Downey BR (1991) Presence of follicular fluid in the porcine oviduct and its contribution to the acrosome reaction Molecular Reproduction and Development 30 148-153

Hunter RHF, Cook B and Poyser NL (1983) Regulation of oviduct function in pigs by local transfer of ovarian steroids and prostaglandins: a mechanism to influence sperm transport European Journal of Obstetrics, Gynaecology and Reproductive Biology 14 225-232

Hyne RV and Garbers DL (1979) Regulation of guinea pig sperm adenylate cyclase by calcium Biology of Reproduction 21 1135-1142

Ignotz GG, Lo MC, Perez CL, Gwathmey TM and Suarez SS (2001) Characterization of a fucose-binding protein from bull sperm and seminal plasma that may be responsible for formation of the oviductal sperm reservoir Biology of Reproduction 64 1806-1811

Jansen RPS (1978) Fallopian tube isthmic mucus and ovum transport Science 201 349-351
Jansen RPS (1980) Cyclic changes in the human Fallopian tube isthmus and their functional importance American Journal of Obstetrics and Gynecology 136 292-308

Johnson LL, Katz DF and Overstreet JW (1981) The movement characteristics of rabbit spermatozoa before and after activation Gamete Research 4 275-282

Katz DF and Yanagimachi R (1980) Movement characteristics of hamster spermatozoa within the oviduct Biology of Reproduction 22 759-764

Kay VJ, Coutts JRT and Robertson L (1994) Effects of pentoxifylline and progesterone on human sperm capacitation and acrosome reaction Human Reproduction 9 2318-2323

Lindemann CB and Goltz JS (1988) Calcium regulation of flagellar curvature and swimming pattern in Triton X-100 extracted rat sperm Cell Motility and the Cytoskeleton 10 420-431

Lindemann CB, Kanous KS and Gardner TK (1991) The interrelationship of calcium and CAMP mediated effects on reactivated mammalian sperm models. In Comparative Spermatology: 20 Years After pp 491-496 Ed. B Baccetti. Raven Press, New York

Mahony MC and Gwathmey T (1999) Protein tyrosine phosphorylation during hyperactivated motility of cynomolgus monkey (Macaca fascicularis) spermatozoa Biology of Reproduction 60 1239-1243

Moore HDM and Taggart DA (1993) In vitro fertilization and embryo culture in the grey short-tailed opossum, Monodelphis domestica. Journal of Reproduction and Fertility 98 267-274

Mortimer ST and Maxwell WM (1999) Kinematic definition of ram sperm hyperactivation Reproduction, Fertility and Development 11 25-30

Mortimer ST and Swan MA (1995) Kinematics of capacitating human spermatozoa analysed at $60 \mathrm{~Hz}$ Human Reproduction 10 873-879

Mujica A, Neri-Bazan L, Tash J and Uribe S (1994) Mechanism for procaine-mediated hyperactivated motility in guinea pig spermatozoa Molecular Reproduction and Development 38 285-292

Neill J and Olds-Clarke P (1987) A computer-assisted assay for mouse sperm hyperactivation demonstrates that bicarbonate but not bovine serum albumin is required Gamete Research 18 121-140

Nichol R, Hunter RHF, Leese HJ and Cooke GM (1992) Concentrations of energy substrates in porcine oviduct fluid and blood plasma during the peri-ovulatory period Journal of Reproduction and Fertility 96 699-707

Okamura N, Tajima Y, Soejima A, Masuda H and Sugita Y (1985) Sodium bicarbonate in seminal plasma stimulates the motility of mammalian spermatozoa through direct activation of adenylate cyclase Journal of Biological Chemistry $2609699-9705$

Olds-Clarke P (1989) Sperm from $t^{\mathrm{w} 32} /+$ mice: capacitation is normal, but hyperactivation is premature and non-hyperactivated sperm are slow Developmental Biology 131 475-482

Pace U, Hanski E, Salomon Y and Lancet D (1985) Odorant-sensitive adenylate cyclase may mediate olfactory reception Nature 316 255-258

Phillips DM (1972) Comparative analysis of mammalian sperm motility Journal of Cell Biology 53 561-573

*Ralt D, Manor M, Cohen-Dayag A et al. (1994) Chemotaxis and chemokinesis of human spermatozoa to follicular factors Biology of Reproduction $\mathbf{5 0} 774-785$

Si Y (1999) Hyperactivation of hamster sperm motility by temperaturedependent tyrosine phosphorylation of an 80-kDa protein Biology of Reproduction 61 247-252

Si Y and Okuno M (1999) Role of tyrosine phosphorylation of flagellar proteins in hamster sperm hyperactivation Biology of Reproduction $\mathbf{6 1}$ 240-246

Stauss CR, Votta TJ and Suarez SS (1995) Sperm motility hyperactivation facilitates penetration of the hamster zona pellucida Biology of Reproduction 53 1280-1285

Suarez SS (1988) Hamster sperm motility transformation during development of hyperactivation in vitro and epididymal maturation Gamete Research 19 51-65

Suarez SS and Dai XB (1992) Hyperactivation enhances mouse sperm capacity for penetrating viscoelastic media Biology of Reproduction $\mathbf{4 6}$ $686-691$

Suarez SS and Osman RA (1987) Initiation of hyperactivated flagellar bending in mouse sperm within the female reproductive tract Biology of Reproduction 36 1191-1198 
Suarez SS, Vincenti L and Ceglia MW (1987) Hyperactivated motility induced in mouse sperm by calcium ionophore A23187 is reversible Journal of Experimental Zoology 244 331-336

*Suarez SS, Katz DF, Owen DH, Andrew JB and Powell RL (1991) Evidence for the function of hyperactivated motility in sperm Biology of Reproduction 44 375-381

Suarez SS, Dai XB, DeMott RP, Redfern K and Mirando MA (1992) Movement characteristics of boar sperm obtained from the oviduct or hyperactivated in vitro. Journal of Andrology 13 75-80

*Suarez SS, Varosi SM and Dai X (1993) Intracellular calcium increases with hyperactivation in intact, moving hamster sperm and oscillates with the flagellar beat cycle Proceedings National Academy of Sciences USA 90 4660-4664

Suarez SS, Brockman K and Lefebvre R (1997) Distribution of mucus and sperm in bovine oviducts after artificial insemination Biology of Reproduction 56 447-453

Suarez SS, Revah I, Lo M and Koelle S (1998) Bull sperm binding to oviductal epithelium is mediated by a $\mathrm{Ca}^{2+}$-dependent lectin on sperm that recognizes Lewis ${ }^{\text {a }}$ trisaccharide Biology of Reproduction 59 39-44

Sueldo CE, Oehninger S, Subias E, Mahony M, Alexander NJ, Burkman LJ and Acosta AA (1993) Effect of progesterone on human zona pellucida sperm binding and oocyte penetrating capacity Fertility and Sterility 60 137-140

Tash JS (1989) Protein phosphorylation: the second messenger signal transducer of flagellar motility Cell Motility and the Cytoskeleton 14 332-339
Tessler S and Olds-Clarke P (1985) Linear and nonlinear mouse sperm motility patterns Journal of Andrology 6 35-44

Vanderhaeghen P, Schurmans S, Vassart G and Parmentier M (1993) Olfactory receptors are displayed on dog mature sperm cells Journal of Cell Biology 123 1441-1452

*Walensky LD and Snyder SH (1995) Inositol 1,4,5-trisphosphate receptors selectively localized to the acrosomes of mammalian sperm Journal of Cell Biology 130 857-869

Walensky LD, Roskams AJ, Lefkowitz RJ, Snyder SH and Ronnett GV (1995) Odorant receptors and desensitization proteins co-localize in mammalian sperm Molecular Medicine 1 130-141

White DR and Aitken RJ (1989) Relationship between calcium, cyclic AMP, ATP, and intracellular $\mathrm{pH}$ and the capacity of hamster spermatozoa to express hyperactivated motility Gamete Research 22 163-177

*Wiesner B, Weiner J, Middendorff R, Hagen V, Kaupp UB and Weyand I (1998) Cyclic nucleotide-gated channels on the flagellum control $\mathrm{Ca}^{2+}$ entry into sperm Journal of Cell Biology 142 473-484

Yanagimachi R (1969) In vitro capacitation of hamster spermatozoa by follicular fluid Journal of Reproduction and Fertility 18 275-286

*Yanagimachi R (1994) Mammalian fertilization. In The Physiology of Reproduction pp 189-317 Eds E Knobil and JD Neill. Raven Press, New York

Yao Y, Ho P and Yeung WS (2000) Effects of human follicular fluid on the capacitation and motility of human spermatozoa Fertility and Sterility $\mathbf{7 3}$ 680-686 